\title{
Fatores determinantes das florações de cianobactérias na água do Rio Doce, Minas Gerais, Brasil
}

\author{
Determinants of cyanobacteria's bloom \\ in water at Doce River, Minas Gerais, Brazil \\ Fernando Antônio Jardim', Eduardo von Sperling², \\ Bárbara Fernanda de Melo Jardim ${ }^{3}$, Katiane Cristina de Brito Almeida ${ }^{4}$
}

\begin{abstract}
RESUMO
A partir de 2005 ocorreram sucessivas florações de cianobactérias tóxicas e não tóxicas na água do Rio Doce. Naquela época, foram identificadas as possíveis causas dessas florações e dentre elas se destacou principalmente o extenso período estival na região da bacia hidrográfica. O principal objetivo desse trabalho foi o de associar estatisticamente alguns parâmetros ambientais e de qualidade da água do rio em um período de cinco anos, para encontrar e explicar as possíveis correlações existentes. As cianobactérias estiveram presentes na água do Rio Doce nos 10 pontos de coleta avaliados pelo Instituto Mineiro de Gestão das Águas, no período de 2008 a 2012. Na análise de agrupamentos entre as estações de coleta, o ponto RD44 se destacou isoladamente e apresentou maiores densidades de termotolerantes durante o inverno. Por meio da análise de componentes principais, verificou-se que as maiores densidades de cianobactérias estiveram associadas a reduções da temperatura da água, da turbidez, da concentração de fósforo total e condições características do período estival (inverno seco) na água de rios em Minas Gerais. Nesse mesmo período, ocorreram elevações nas concentrações de clorofila a, oxigênio dissolvido, nitratos, da relação estequiométrica N/P e do Índice de Qualidade das Águas. Após 2009 as florações se tornaram sucessivas. Isso reforça a teoria de que o represamento da água do rio exerceu uma influência nas crescentes florações de cianobactérias, pois podem ter contribuído para a redução da turbidez da água do rio, para o aumento da concentração de nitratos e da densidade de termotolerantes.
\end{abstract}

Palavras-chave: florações de cianobactérias; fatores abióticos; Rio Doce.

\begin{abstract}
From 2005 there were successive blooms of toxic and nontoxic cyanobacteria in water from Doce River. At that time, the possible causes of these blooms were studied and the extensive winter period in the watershed area was one of the main causes. The main objective of this study was to statistically associate some quality and environmental parameters of the river water for a period of five years, to meet and explain the possible correlations. Cyanobacteria were present in the water of the Doce River in the 10 sampling points evaluated in the period from 2008 to 2012. In cluster analysis between the collection points, the sample station RD44 stood alone and presented during the dry seasons of the years the highest densities of thermotolerant coliform. By means of principal component analysis, it was found that increased density of cyanobacteria was associated with a reduction in temperature of the water, turbidity and the concentration of phosphorus, which are characteristic conditions of river waters in Minas Gerais during the winter period (dry season). In the same period, there were increases in the concentrations of chlorophyll a, dissolved oxygen, nitrates, the stoichiometric ratio N/P and the Water Quality Index. After 2009, successive cyanobacteria blooms have been registered. This reinforces the theory that the damming of the river has had a growing influence on cyanobacteria blooms. They may have contributed to reduce the turbidity of river water, increase in nitrate concentration and thermotolerant coliform density.
\end{abstract}

Keywords: cyanobacteria blooms; abiotic factors; Doce River.

Trabalho realizado no laboratório Central da COPASA - Belo Horizonte (MG), Brasil.

Biólogo. Mestre em Saneamento, Meio Ambiente e Recursos Hídricos pela Escola de Engenharia da Universidade Federal de Minas Gerais (UFMG). Doutor em Biologia Vegetal pela UFMG. Responsável pelo setor de Biologia do laboratório Central da Companhia de Saneamento de Minas Gerais (COPASA MG) - Belo Horizonte (MG), Brasil. ²Engenheiro Civil. Mestre em Engenharia Sanitária pela UFMG. Doutor em Limnologia pela Universidade Técnica de Berlim - Berlim, Alemanha. Professor Titular do Departamento de Engenharia Sanitária e Ambiental da UFMG - Belo Horizonte (MG), Brasil.

${ }^{3}$ Bióloga. Mestre em Engenharia Sanitária e Ambiental pela UFMG. Analista ambiental na Gerência de Estudos e Manejo da Ictiofauna e Programas Especiais da Companhia Energética de Minas Gerais (CEMIG) - Belo Horizonte (MG), Brasil.

${ }^{4}$ Bióloga. Mestre em Saneamento, Meio Ambiente e Recursos Hídricos pela Escola de Engenharia da UFMG. Analista ambiental do Instituto Mineiro de Gestão de Águas (IGAM) e coordenadora do programa Águas de Minas - Belo Horizonte (MG), Brasil.

Endereço para correspondência: Fernando Antônio Jardim - Rua Professor Mamede, 85 - 30730-270 - Belo Horizonte (MG), Brasil - E-mail: fernando.jardim@copasa.com.br Recebido: 21/05/13 - Aceito: 14/11/13 - Reg. ABES: 1026 


\section{INTRODUÇÃO}

Apesar da escassez de trabalhos relativos às florações de cianobactérias nas águas de ambientes lóticos no Brasil, há evidências de que essas florações estejam associadas a extensos períodos estivais, nos quais a ausência de chuvas provoca uma baixa taxa de escoamento da água. Esse fenômeno natural, associado a um balanço ideal de nutrientes e à elevação da temperatura, pode propiciar condições favoráveis à ocorrência de florações de algas e de cianobactérias na água de rios. Costelloe et al. (2005) e Oliver et al. (2009) relacionaram o aumento na concentração de nutrientes e a redução da turbidez na água como sendo as principais causas das florações de cianobactérias nas águas de rios das bacias do Lago Eyre e nas águas do Rio Murray, situados na Austrália. Maier et al. (2001) provaram que a persistência das florações de cianobactérias nas águas do Rio Murray era diretamente relacionada com a existência de uma estratificação térmica na coluna d'água e, assim que era atingida a isotermia, havia uma redução na intensidade das florações. No Brasil, estudos realizados por Soares et al. (2007) confirmaram o predomínio de Cylindrospermopsis raciborskii nas águas do rio Paraibuna, no sudeste brasileiro, no período estival. Jardim et al. (2008), Von Sperling e Jardim (2009), Jardim (2011) e Ferraz (2012) relacionaram o longo período de estiagem a um aumento na concentração de nutrientes na água do rio das Velhas, em Minas Gerais, como sendo as principais causas de uma florações tóxicas na água desse rio. A bacia do Rio Doce situa-se no sudeste brasileiro, compreendendo uma área de $83.400 \mathrm{~km}^{2}$. A região abrange cerca de 220 municípios e o rio é formado pela junção do Rio do Carmo com o Rio Piranga. Possui uma extensão de $853 \mathrm{~km}$ e o seu aproveitamento energético teve início em setembro de 2004 com o enchimento da Usina Hidrelétrica
(UHE) Rizoleta Neves, que se localiza no alto Rio Doce. Dois anos depois, em maio de 2006, entrou em operação a UHE Aimorés, que se localiza na cidade de Aimorés. Já em setembro de 2009, iniciou-se o funcionamento da UHE Baguari, que se localiza no médio rio Doce, próxima à cidade de Governador Valadares. Na Tabela 1 foram destacadas cidades com a população acima de 20 mil habitantes, com a produção teórica dos esgotos domésticos gerados, enfatizando-se as cargas de nitrogênio e fósforo produzidas. Não foram consideradas na tabela as cargas de nutrientes oriundas de outras atividades.

De acordo com relatórios internos da COPASA (2005 a 2012), as florações de cianobactérias na água do rio tiveram início em outubro de 2005, com o predomínio de C. raciborskii produzindo saxitoxinas. Em julho de 2007, a floração foi de Aphanocapsa sp., que não apresentou toxicidade. Em setembro de 2009, registrou-se novamente o predomínio de C. raciborskii neurotóxica. A partir do mês de julho até o mês de outubro dos anos de 2010, 2011 e 2012, ocorreram maiores densidades de Dolichospermum planctonicum e $D$. solitarium ao longo do rio Doce (ANA, 2012), que apesar de serem não tóxicas são produtoras de terpenos (2-metil isoborneol). Desta forma, o principal objetivo desse trabalho foi o de avaliar quais foram os fatores que mais influenciaram para a ocorrência e a manutenção das florações de cianobactérias na água do Rio Doce.

\section{METODOLOGIA}

Na bacia do rio Doce são monitorados 64 (sessenta e quatro) pontos (Figura 1) trimestralmente pelo Instituto Mineiro de Gestão de

Tabela 1 - Cidades da bacia do Rio Doce com a população superior a 20 mil habitantes, a carga de esgoto diária e o percentual de tratamento.

\begin{tabular}{|c|c|c|c|c|c|}
\hline \multirow{2}{*}{ Cidades } & \multirow{2}{*}{ População } & \multicolumn{4}{|c|}{ Esgoto gerado (T.dia') } \\
\hline & & Nitrogênio & Fósforo & Total & $\%$ de tratamento \\
\hline Ouro Preto & 70.227 & 0,632 & 0,177 & 0,809 & $\mathrm{O}$ \\
\hline Mariana & 54.179 & 0,488 & 0,137 & 0,624 & 0 \\
\hline Viçosa & 72.244 & 0,650 & 0,182 & 0,832 & 0 \\
\hline Ponte Nova & 57.361 & 0,516 & 0,145 & 0,661 & $\mathrm{O}$ \\
\hline Timóteo & 81.119 & 0,730 & 0,204 & 0,934 & $\mathrm{O}$ \\
\hline Ipatinga & 239.177 & 2,153 & 0,603 & 2,755 & 100 \\
\hline Coronel Fabriciano & 104.173 & 0,938 & 0,263 & 1,200 & 0 \\
\hline Governador Valadares & 263.594 & 2,372 & 0,664 & 3,037 & 0 \\
\hline Caratinga & 85.322 & 0,768 & 0,215 & 0,983 & $\mathrm{O}$ \\
\hline Conselheiro Pena & 22.579 & 0,203 & 0,057 & 0,260 & 0 \\
\hline Aimorés & 24.937 & 0,224 & 0,063 & 0,287 & 0 \\
\hline Pedra Corrida, Alpercata,Tumiritinga, Resplendor e Itueta & 37.328 & 0,336 & 0,094 & 0,430 & O \\
\hline Total & 1.112 .240 & 10,01 & 2,803 & 12,813 & 21,5 \\
\hline
\end{tabular}

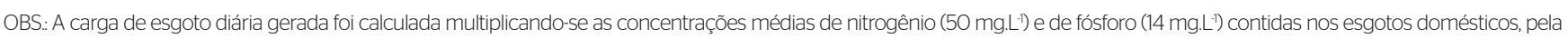
produção per capta (180 L.dia') e o número de habitantes. Fonte (população): Sinopse do censo demográfico, 2010: Minas Gerais (IBGE 2010). 


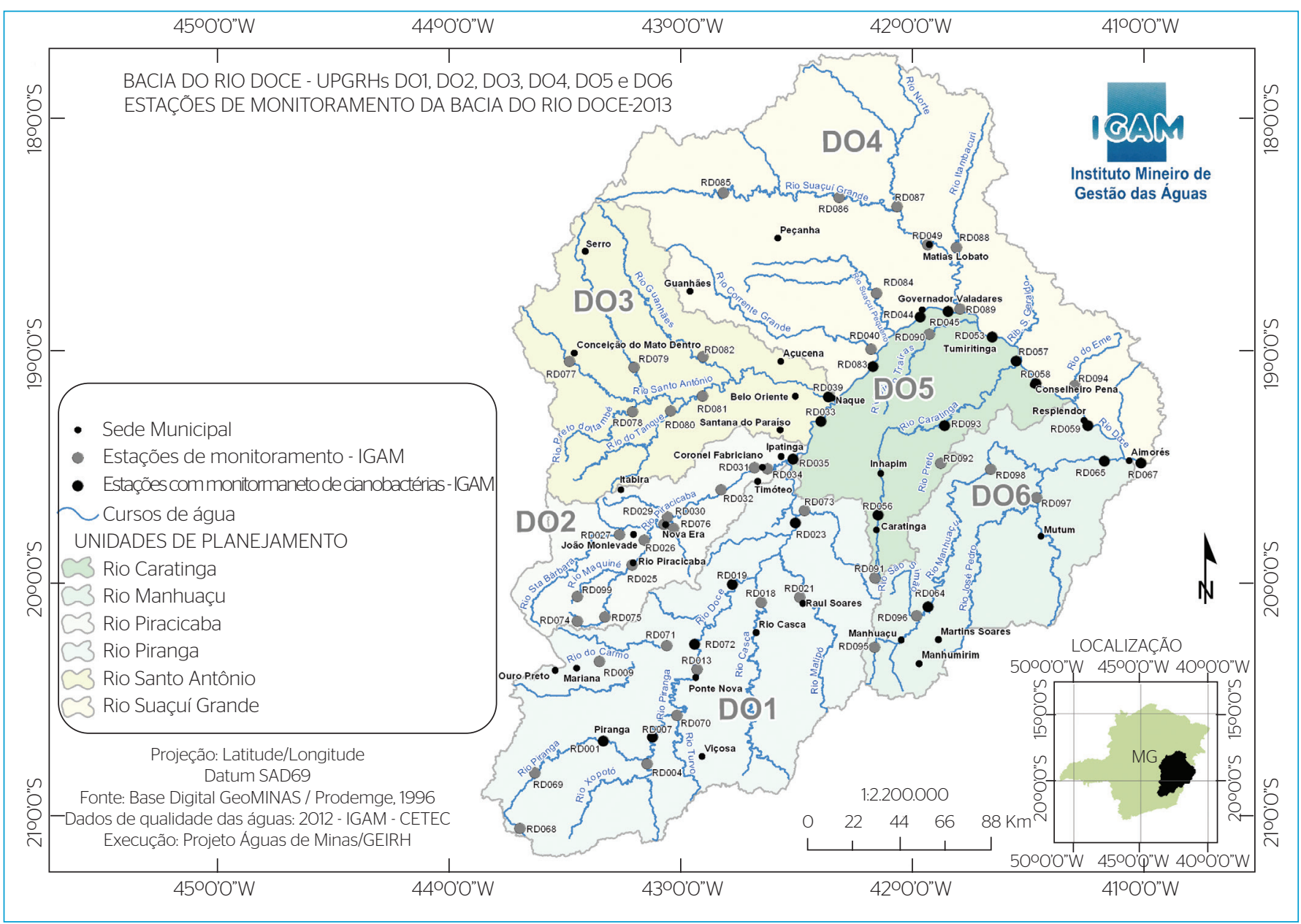

Figura 1 - Mapa da bacia hidrográfica do Rio Doce com a indicação dos pontos de amostragem da rede de monitoramento do IGAM. Fonte: IGAM (2013).

Águas (IGAM), dos quais 10, situados na calha do Rio Doce, possuem amostragem de cianobactérias. O período de monitoramento utilizado no presente estudo foi de 1997 a 2012, priorizando-se os dados a partir de 2008 em virtude da disponibilidade dos dados das densidades de cianobactérias. A Tabela 2 apresenta a descrição das estações de monitoramento selecionadas para o estudo, fornecendo informações de localização dos pontos de monitoramento. A Figura 1 mostra a localização das estações monitoradas pelo IGAM na bacia do Rio Doce, destacando as que possuem amostragem de cianobactérias.

Para a seleção dos pontos estudados, além da necessidade da existência de dados analíticos de cianobactérias e dos parâmetros físico-químicos, definiu-se também como critério pontos onde, durante o período de monitoramento, ocorreram densidades de células de cianobactérias superiores a 2.000 células. $\mathrm{mL}^{-1}$, pois com esse limite a incerteza do método não ultrapassou de 10\% (COPASA, 2011). Foram selecionados para o presente estudo os seguintes parâmetros: temperatura da água, nitrato, demanda bioquímica de oxigênio, oxigênio dissolvido, ortofosfatos, nitrogênio amoniacal e orgânico, turbidez, fitoplâncton e clorofila $a$ (APHA, 2012), além do Índice de Qualidade das Águas (IQA), desenvolvido pela National Sanitation Foundation dos Estados Unidos (IGAM, 2009). Foi também calculada a relação estequiométrica entre as concentrações de nitrogênio total e de fósforo total. Foram utilizados dados trimestrais dos parâmetros físicos e químicos, obtidos no período de janeiro de 2008 a abril de 2012, para as análises dos agrupamentos e a de componentes principais. As análises de agrupamento hierárquico e de componentes principais foram empregadas para agrupar os pontos de monitoramento selecionados para o estudo na bacia do Rio Doce, de acordo com similaridades e índices de qualidade de água. A análise de Agrupamentos (cluster) é uma técnica estatística multivariada que permite separar ou classificar objetos observados em um grupo ou em número específico de subgrupos mutuamente exclusivos, de modo que os subgrupos formados tenham características de grande similaridade interna e grande dissimilaridade externa. Como os dados não possuíam a mesma escala numérica de medida, foi realizada a padronização prévia dos 
Tabela 2 - Pontos de monitoramento de qualidade de água no Rio Doce selecionados no estudo.

\begin{tabular}{|c|c|c|c|c|}
\hline Pontos & Localização & \multicolumn{2}{|c|}{ Coordenadas geográficas } & $\begin{array}{l}\text { Altitude } \\
(\mathrm{m})\end{array}$ \\
\hline RD 19 & $\begin{array}{l}\text { Rio Doce à montante } \\
\text { da foz do Rio Casca }\end{array}$ & 200.111,18"S & $42^{\circ}, 44^{\prime \prime} 40,69^{\prime \prime} \mathrm{O}$ & 280 \\
\hline RD 23 & $\begin{array}{l}\text { Rio Doce à montante } \\
\text { da comunidade de } \\
\text { Cachoeira dos Óculos }\end{array}$ & $190.33^{\prime} 15,05^{\prime \prime S}$ & $420.3117,70 " 0$ & 225 \\
\hline RD 35 & $\begin{array}{l}\text { Rio Doce à jusante do } \\
\text { Ribeirão Ipanema eà } \\
\text { jusante da confluência } \\
\text { com o Rio Piracicaba }\end{array}$ & $190.2844,54 " S$ & $42 \circ .2841,51 " 0$ & 213 \\
\hline RD 33 & $\begin{array}{l}\text { Rio Doce à jusante da } \\
\text { cachoeira escura. }\end{array}$ & 190.19'7,65”S & $420.2148,00 " 0$ & 198 \\
\hline RD 44 & $\begin{array}{l}\text { Rio Doce na cidade de } \\
\text { Governador Valadares }\end{array}$ & 180.52 '54,91"S & $410.51339,98 " \mathrm{O}$ & 163 \\
\hline RD 45 & $\begin{array}{c}\text { Rio Doce à jusante da } \\
\text { cidade de Governador } \\
\text { Valadares }\end{array}$ & 180.5110,23”S & $410.5744,67 " O$ & 146 \\
\hline RD 53 & $\begin{array}{l}\text { Rio Doce à jusante do } \\
\text { Rio Suaçui Grande, em } \\
\text { Tumiritinga. }\end{array}$ & $180.5826,24 " S$ & $410.3828,49^{\prime \prime} \mathrm{O}$ & 128 \\
\hline RD 58 & $\begin{array}{l}\text { Rio Doce na cidade de } \\
\text { Conselheiro Pena }\end{array}$ & 190.10’0,72"S & $410.282,55^{\prime \prime} \mathrm{O}$ & 114 \\
\hline RD 59 & $\begin{array}{l}\text { Rio Doce à jusante de } \\
\text { Resplendor }\end{array}$ & $190.20 \prime 42,99 " S$ & 410.14'30,10"O & 88 \\
\hline RD 67 & $\begin{array}{l}\text { Rio Doce em Aimorés } \\
\text { (MG)/Baixo Guandu (ES) }\end{array}$ & 190.29’22,O1”S & 419.03’20,07"O & 69 \\
\hline
\end{tabular}

Fontes: IGAM (2009) e Google Earth (2013). dados multiplicando-se as variáveis por $(\log \mathrm{x}+1)$ de acordo com Ferraz (2012). A distância Euclidiana foi utilizada para medir a ligação dos agrupamentos e assim verificar quais pontos de monitoramento apresentaram maiores similaridades em relação aos parâmetros testados. Visando verificar a homogeneidade dentro do grupo e a heterogeneidade entre os grupos foi utilizado o método de encadeamento (single linkage) pelo agrupamento hierárquico aglomerativo. $\mathrm{Na}$ análise de componentes principais foram agrupados os dados analíticos similares entre os pontos de coleta (estações amostrais) e os parâmetros de qualidade da água, sendo realizado também o teste scree (plot scree) para definir o número de componentes que deveriam ser considerados. Para o tratamento estatístico, visando avaliar a significância das correlações obtidas, foi utilizada a análise de correlação de Spearman para dados não paramétricos com a significância de 5\% (Statistica 6.1). Alguns valores foram eventualmente transformados em escala logarítmica, a fim de uma melhor representação gráfica.

\section{RESULTADOS E DISCUSSÃO}

De acordo com os resultados das análises de cianobactérias para a seleção dos pontos de coleta para o presente estudo, verificou-se que a densidade de células por mililitro foi superiores a 2.000 em todos os pontos, demonstrados na Figura 2.

Foi verificada uma sazonalidade na distribuição das densidades de cianobactérias sendo que os maiores valores nos dez pontos monitorados pelo IGAM representam o período estival.

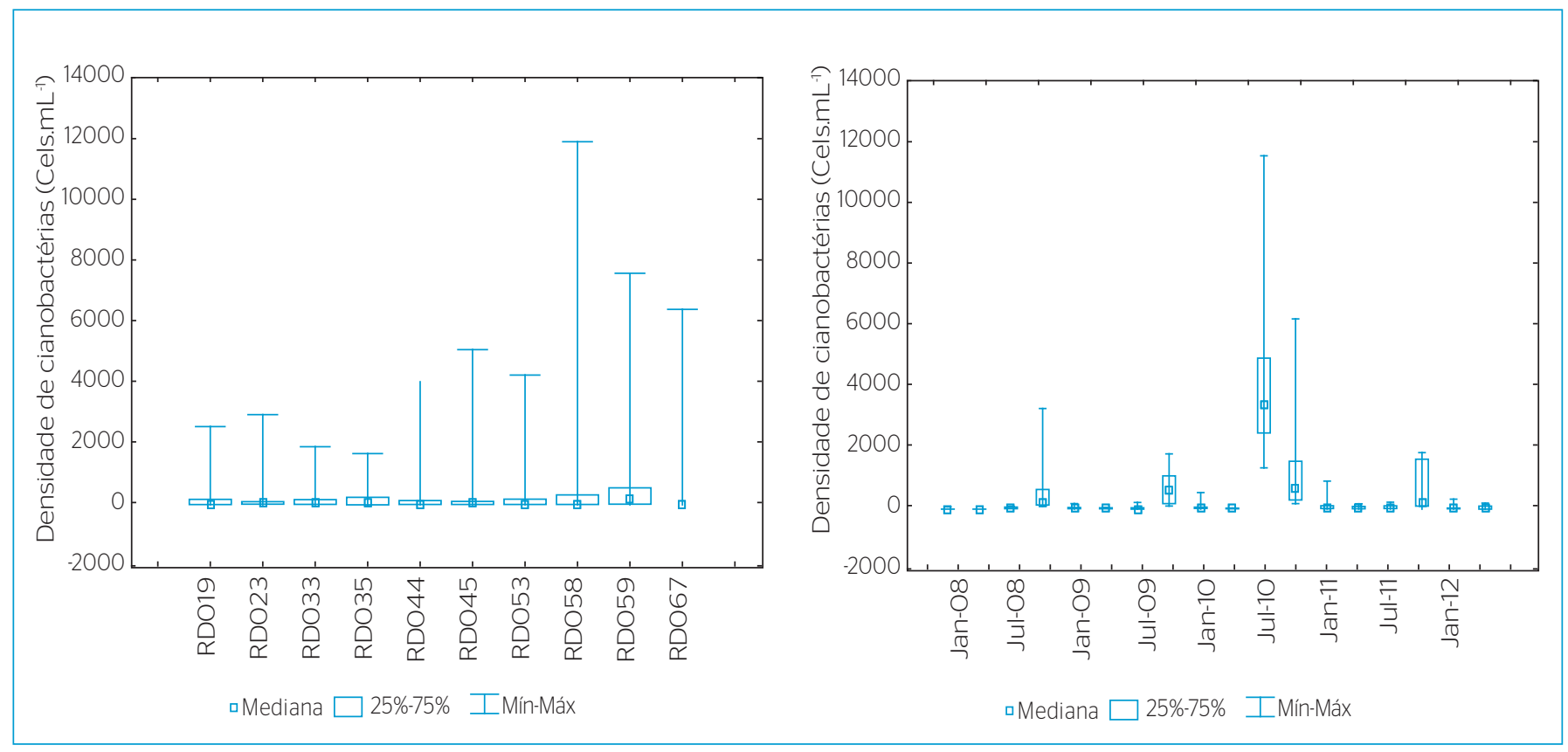

Figura 2 - Variações das densidades de cianobactérias nos pontos avaliados no Rio Doce, entre 1997 e 2008 e ao longo dos meses no período de 2008 a 2012. 
Outra importante observação se refere ao aumento gradativo da densidade de cianobactérias nos pontos de monitoramento do Rio Doce, de montante à jusante. De acordo com esse monitoramento a densidade de células não passou de 14.000. cel.mL $\mathrm{m}^{-1}$. No entanto, de acordo com COPASA (2005 a 2012), em datas mais próximas das florações foi possível determinar até $10^{6}$ celulas. $\mathrm{mL}^{-1} \mathrm{em}$ alguns pontos de captação de água. A análise de agrupamento realizada com o objetivo de agrupar os pontos de amostragem de acordo com suas semelhanças em relação aos resultados das análises obtidas é apresentada no dendrograma exibido na Figura 3.

Para determinar o corte no gráfico que determina o número de grupos, procedeu-se como recomendado por Vicini (2005). $\mathrm{Na}$ análise em conjunto do gráfico de distâncias (Figura 4) com a Tabela 3, que mostra os valores de ligação entre as variáveis, foi possível observar que o maior salto $(2,25)$ ocorre entre os passos de agrupamento 9 e 10, que correspondem às distâncias de ligação 5,92 e 8,17. A linha Fenon (linha de corte) foi traçada, então, entre essas duas distâncias, no valor médio de 7,04, como apresentado no dendrograma da Figura 3.

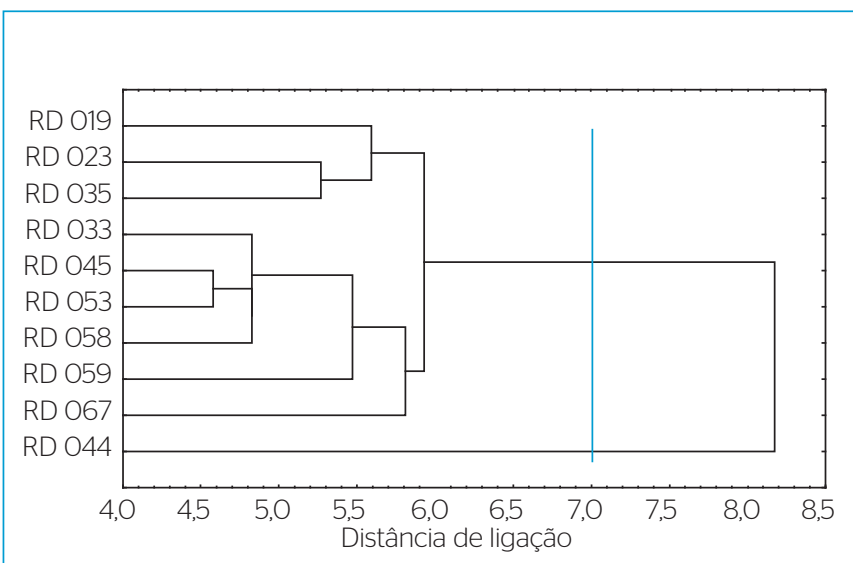

Figura 3-Resultados da análise de agrupamento entre as estações de coleta na água do Rio Doce no período de 2008 a 2012 com 12 variáveis e 183 casos.
$\mathrm{Na}$ distância de ligação igual a 7 foi possível verificar a formação, à princípio, de dois agrupamentos entre as estações de coleta em função das semelhanças entre os resultados das análises de qualidade da água. O primeiro agrupamento foi formado isoladamente pelo ponto de coleta RD 44. Já o segundo foi formado por dois subgrupos bem definidos: RD19, RD23 e RD35 e o outro RD33, RD45, RD53, RD58, RD59 e o RD67.

Verificou-se também um agrupamento das estações de amostragem entre os RD19, RD23 e 35 que estão localizados respectivamente a 280,225 e 213 metros de altitude, em regiões de corredeiras. Embora apresentassem elevadas concentrações de fósforo total, o aumento do fluxo da água propiciado pelas corredeiras impediu a formação de florações nesses pontos.

O resultado da análise de agrupamento com o objetivo de agrupar os parâmetros de qualidade da água em função dos resultados das análises está representado na Figura 5.

Observou-se uma intrínseca correlação entre os parâmetros que se referem aos nutrientes na água como o fósforo total, o nitrogênio amoniacal, nitrogênio orgânico, os nitratos e o nitrogênio

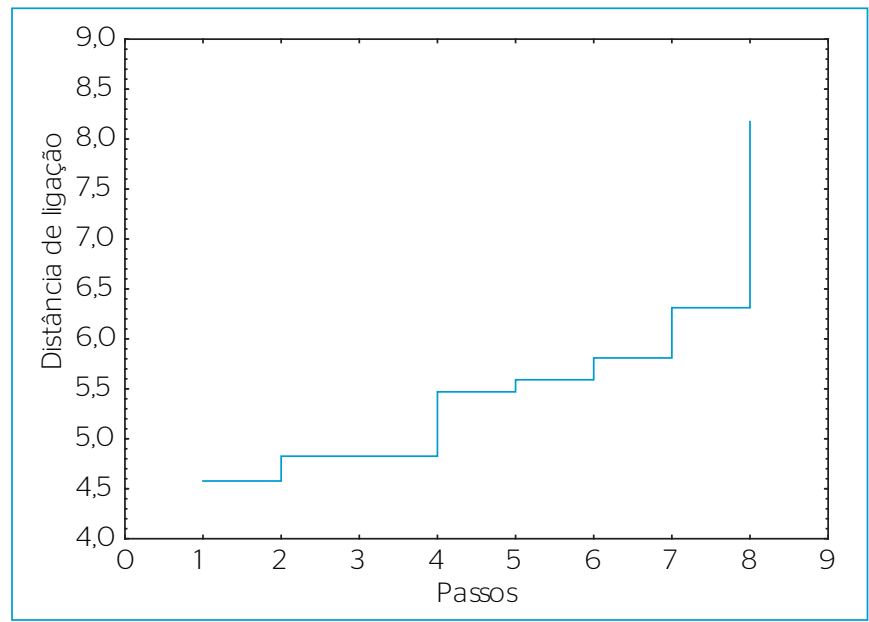

Figura 4 - Gráfico das Distâncias Euclidianas nas quais os grupos foram formados ao longo dos passos de agrupamentos.

Tabela 3 - Valores das distâncias de ligação nas quais os agrupamentos foram formados ao longo dos passos de agrupamento.

\begin{tabular}{l|l|l|l|l|l|l|l|l|l} 
Distância de \\
ligação
\end{tabular}


total, por possuírem a menor distância euclidiana. Em seguida formou-se um segundo agrupamento entre a relação estequiométrica das concentrações de nitrogênio total e o fósforo total (N/P) e os nutrientes, juntamente com a clorofila $a$. No terceiro agrupamento a similaridade ficou entre os parâmetros temperatura da água, a turbidez, o IQA e o oxigênio dissolvido. Devido possivelmente à diferença entre as escalas numéricas dos parâmetros, embora tivessem sido padronizados anteriormente, a densidade de cianobactérias formou sobre os outros parâmetros um quarto agrupamento e em seguida, a densidade de termotolerantes que representa a poluição orgânica fecal e em ambas as unidades foram números exponenciais. Os dados obtidos na matriz de correlação de Spearman entre os parâmetros de qualidade da água e a densidade de cianobactérias constam da Tabela 4.

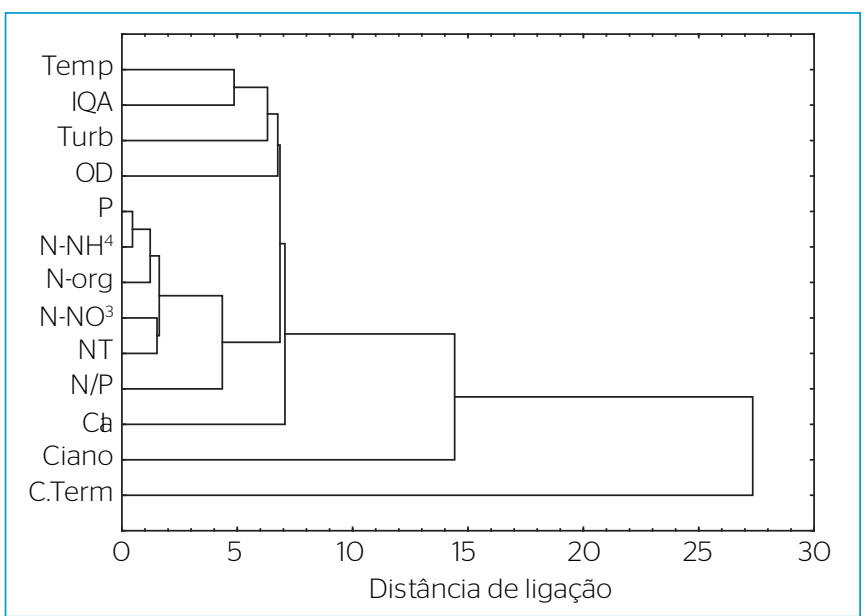

Figura 5 - Resultados da análise de agrupamento entre os parâmetros analisados na água do Rio Doce no período de 2008 a 2012 com 12 variáveis e 183 casos.

Tabela 4 - Resultados da correlação de Spearman entre os parâmetros de qualidade da água e a densidade de cianobactérias na água do Rio Doce, no período de 2008 a 2012.

\begin{tabular}{l|c|c}
\hline Variáveis & Spearman R & Valor $\mathbf{p}$ \\
\hline Temperatura da água & $-0,2277$ & 0,002 \\
\hline Turbidez & $-0,4426$ & 0,000 \\
\hline Oxigênio dissolvido & 0,2899 & 0,000 \\
\hline Fósforo total & $-0,1593$ & 0,031 \\
\hline Nitrogênio - nitrato & 0,1443 & 0,050 \\
\hline Nitrogênio amoniacal & 0,0093 & 0,899 \\
\hline Nitrogênio orgânico & $-0,0835$ & 0,260 \\
\hline Nitrogênio total & 0,0547 & 0,461 \\
\hline Relação N/P & 0,1526 & 0,039 \\
\hline Coliformes termotolerantes & $-0,0751$ & 0,312 \\
\hline Clorofila a & 0,4250 & 0,000 \\
\hline Índice de Qualidade da Água & 0,2253 & 0,002 \\
\hline
\end{tabular}

183 coletas realizadas nos 10 pontos avaliados.
Os resultados obtidos por meio da Análise de Componentes Principais (ACP) estão apresentados na Figura 6.

De acordo com a Figura 6, a densidade de cianobactérias se sobrepôs à concentração de clorofila $a$, indicando ser esse último, um parâmetro indicador para a presença de florações. Quanto maior o IQA, maior foi a densidade de cianobactérias. Isso se deveu possivelmente ao elevado peso para os parâmetros oxigênio dissolvido e $\mathrm{pH}$ no cálculo da fórmula, que apresentaram concentrações mais elevadas e valores mais altos, respectivamente, quando da ocorrência das florações. A concentração de oxigênio dissolvido se sobrepôs à relação $\mathrm{N} / \mathrm{P}$, devido ao aumento do nitrato na água, pois esses resultados se correlacionaram positivamente com a densidade de cianobactérias. As florações de cianobactérias estiveram sempre correlacionadas com as concentrações de nitrato na água (Tabela 4). As florações de cianobactérias na água do rio foram sempre mais proeminentes no final do período estival e no início da estação chuvosa (outubro/novembro), onde há um predomínio na água de nitrogênio orgânico e amoniacal. A densidade de termotolerantes ficou sobreposta à concentração de fósforo total, que por sua vez se correlacionou negativamente com a densidade de cianobactérias. Em rios, quando ocorrem as primeiras chuvas, é comum a contribuição alóctone de fósforo e de termotolerantes. Nesse mesmo quadrante, a temperatura da água e a turbidez se correlacionaram negativamente com a densidade de cianobactérias, indicando a interferência das chuvas, que ao escoarem pela terra durante o verão carreiam para dentro da água do rio partículas sólidas em suspensão, nutrientes e ao mesmo tempo, carreiam

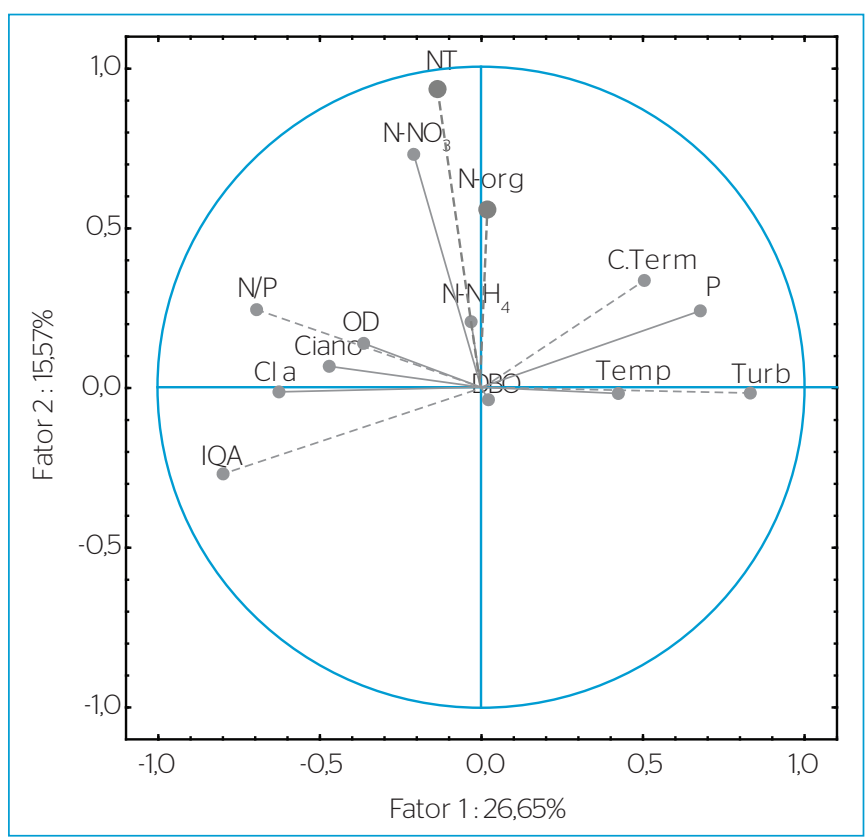

Figura 6 - Resultados da análise de componentes principais dos parâmetros analisados na água do Rio Doce no período de 2008 a 2012 por meio das correlações entre 13 variáveis - 183 casos. 
também as florações de cianobactérias ao longo do leito do rio. Na Figura 7, verificou-se um aumento na concentração de fósforo na água do RD19 que pode estar relacionado a um estreitamento do canal do rio nesse trecho (embaixo da ponte da BR 262) e a presença de áreas agricultáveis.

O ponto RD23 localiza-se à montante da Cachoeira dos Óculos sobre um leito rochoso, recebe o efluente dos esgotos domésticos da comunidade de Revés do Belém. O aumento do fluxo da água (leito rochoso) não permitiu a manutenção de florações de cianobactérias, mas um aumento na concentração de oxigênio dissolvido. Para um melhor entendimento dos gráficos dessa figura e nas subsequentes, observou-se que as concentrações máximas de fósforo de $0,4 \mathrm{mg} . \mathrm{L}^{-1}$ ocorreram nos pontos RD53 (Tumiritinga) e RD67 (Aimorés), nos meses de novembro/99 e janeiro/04, respectivamente, caracterizando assim as maiores concentrações no período chuvoso. Avaliação semelhante pode ser adotada também para o acompanhamento da concentração de oxigênio dissolvido que está representada na Figura 8.

Nesses gráficos verificou-se que as maiores concentrações de oxigênio (10,0 mg.. $\left.\mathrm{L}^{-1}\right)$ foram detectadas nos pontos de coleta situados nos RD33 (à jusante da Cachoeira Escura) e RD59 (Resplendor), respectivamente, nos meses de julho/11 e julho/10, ou seja, as maiores concentrações de oxigênio dissolvido foram encontradas no período estival. O ponto de coleta RD35 recebe os efluentes tratados da cidade de Ipatinga e os efluentes não tratados de duas cidades populosas e isso refletiu diretamente no IQA, que sempre se manteve abaixo de 60 (Figura 11), com a mediana da turbidez próxima a 100 Unidades Nefelométrica de Turbidez (UNT). A elevada turbidez e a correnteza da água, possivelmente não permitiram a formação de florações. Os pontos de

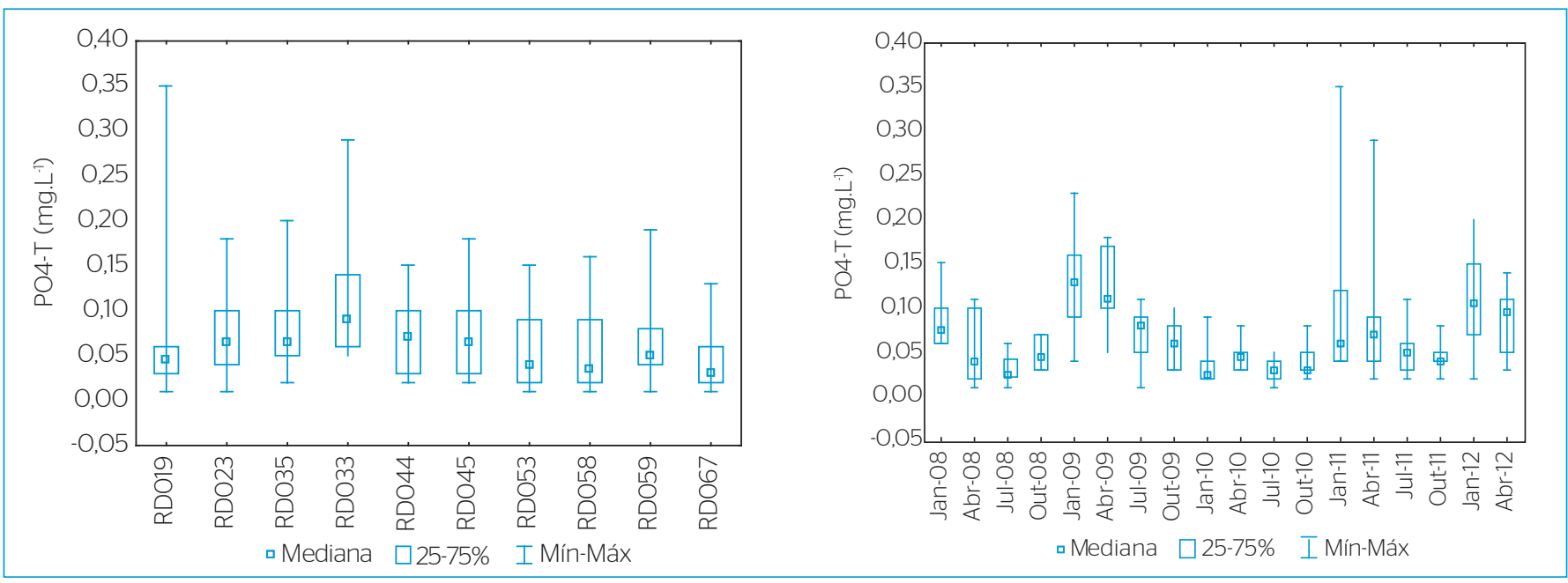

Figura 7 - Variações das concentrações de fósforo total nos pontos avaliados no Rio Doce, entre 1997 e 2008 e ao longo dos meses no período de 2008 a 2012.

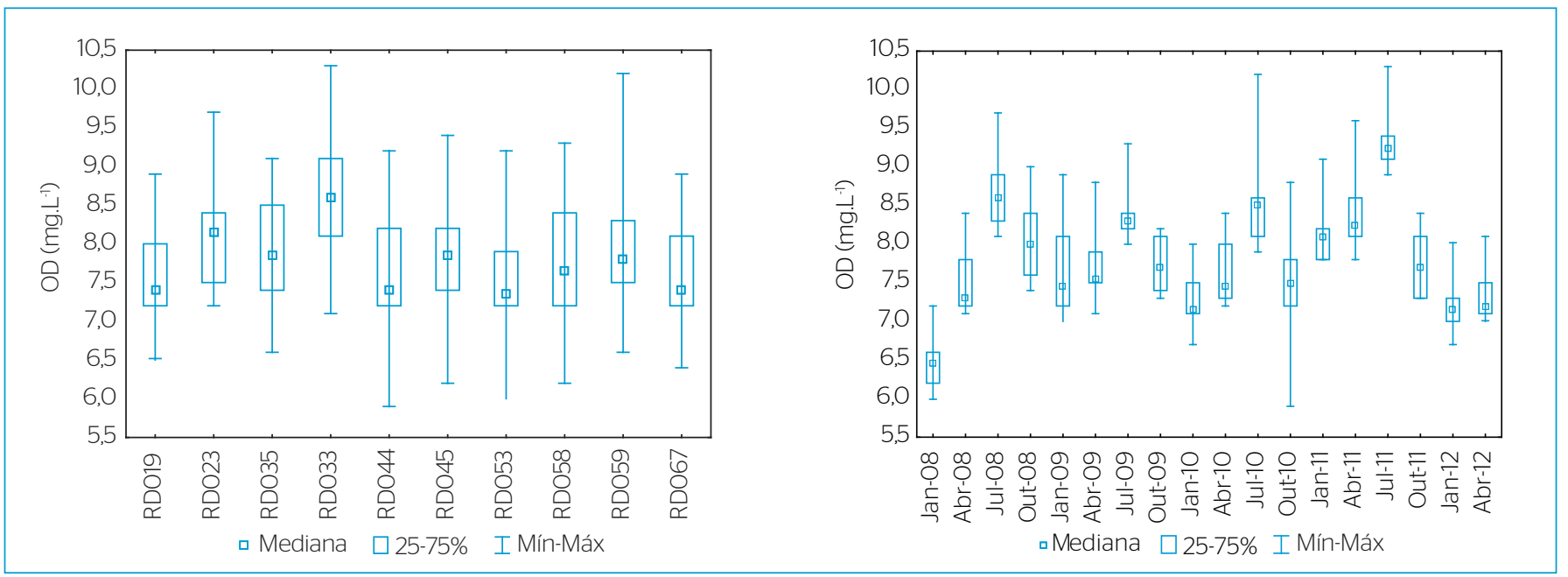

Figura 8 - Variações das concentrações de oxigênio dissolvido nos pontos avaliados no rio Doce, entre 1997 e 2008 e ao longo dos meses no período de 2008 a 2012. 
coleta RD35, RD33, RD44 estão localizados dentro da depressão interplanáltica do rio (CBH DOCE, 2013), onde deságuam os rios Santo Antônio e Corrente Grande. O RD33 recebe os efluentes de uma lagoa de estabilização e isso explica uma elevação na concentração fósforo total no período chuvoso e de oxigênio dissolvido no período estival (Figuras 7 e 8), e também uma elevação da densidade de termotolerantes a partir de outubro de 2008, além do nitrato, a partir de outubro de 2010 e uma redução do IQA, sempre no período chuvoso. As variações desses parâmetros podem ser visualizadas por meio das Figuras 9 a 11.

As densidades de termotolerantes próximas a uma ordem de grandeza de $10^{5} \mathrm{NMP} .100 \mathrm{~mL}^{-1}$ foram registradas em todas as estações amostrais, sempre nos períodos de chuva até 2009. Após esse ano, os pontos de coleta RD23, RD33 e RD45 mantiveram também elevadas densidades no período de seca.

As variações da concentração de nitratos na água do Rio Doce podem ser visualizadas na Figura 10. Observa-se que a concentração de nitratos na água alcançou $0,8 \mathrm{mg} \cdot \mathrm{L}^{-1} \mathrm{em}$ todas as estações de amostragem, predominantemente no período de seca, e nos últimos anos, ficou acima de 1,0 mg. $\mathrm{L}^{-1}$ nas estações amostrais RD19 e RD44.

Os resultados do Índice de Qualidade das Águas são apresentados na Figura 11. Verifica-se que a redução no IQA ocorreu sempre no período chuvoso, devido a uma elevação da turbidez e a uma redução nas concentrações de oxigênio dissolvido (comparando as Figuras 8 e 11).
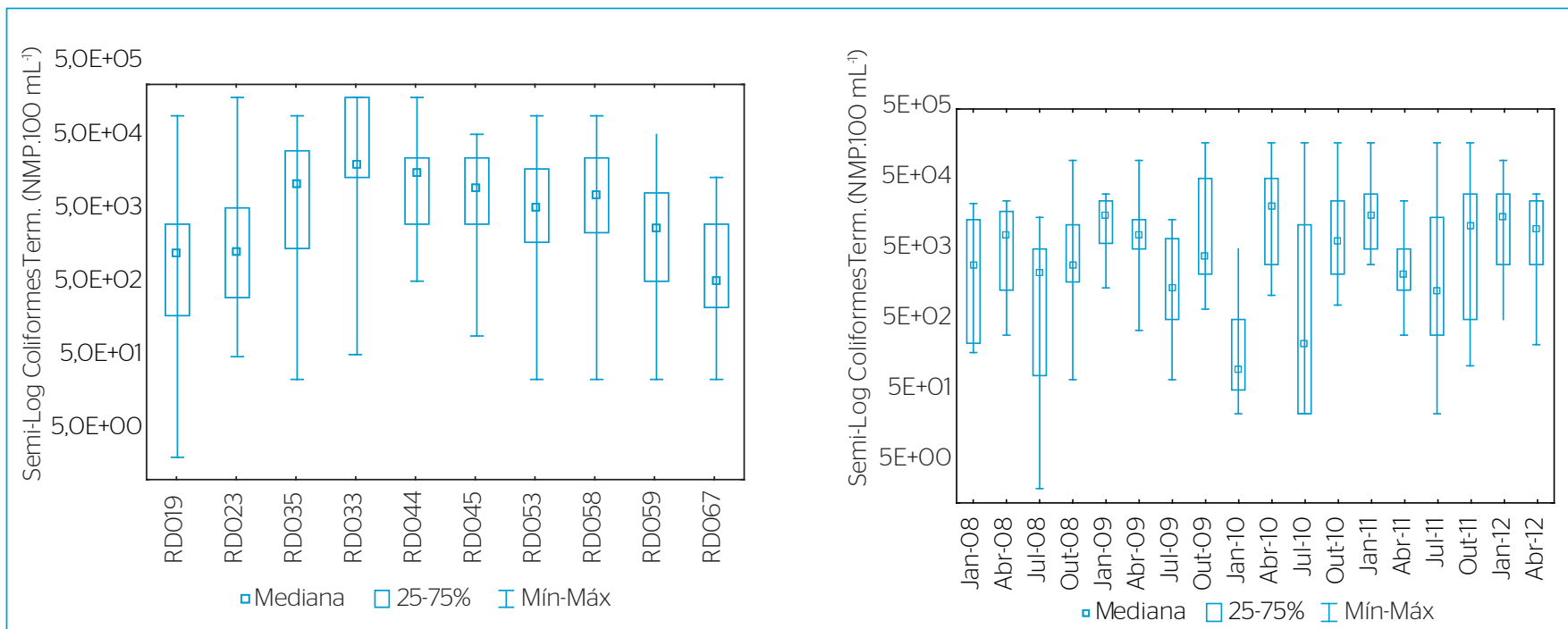

Figura 9 - Variações das densidades de coliformes termotolerantes nos pontos avaliados no Rio Doce, entre 1997 e 2008 e ao longo dos meses no período de 2008 a 2012.

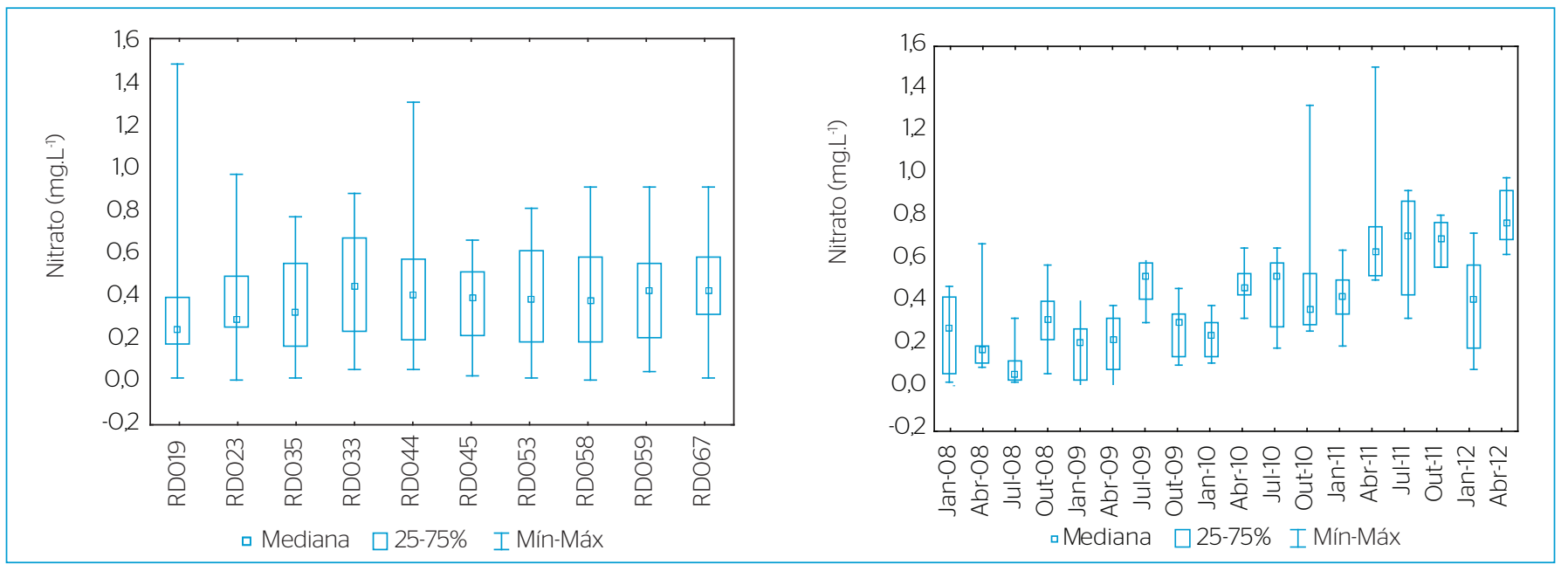

Figura 10 - Variações das concentrações de nitrato nos pontos avaliados no Rio Doce, entre 1997 e 2008 e ao longo dos meses no período de 2008 a 2012. 
Nos últimos três anos a concentração de oxigênio dissolvido aumentou, sempre no período estival, em todos os pontos de coleta, à exceção para o RD19. Essa constatação pode estar relacionada à produção fotossintética das algas e das cianobactérias na água do rio. O ponto de coleta RD45 localiza-se após o RD44, localizado em Governador Valadares. Observaram-se aumentos significativos $(<0,05)$ na concentração de oxigênio dissolvido e consequentemente no IQA e um aumento na concentração de fósforo total entre esses pontos, mas sem nunca haver o registro de florações de cianobactérias até Tumiritinga (RD53). Isso pode ser explicado devido à presença de corredeiras que não permitiram a manutenção dessas florações. Por meio das Figuras 8 e 11 é possível visualizar essas diferenças ao longo do período de estudo.

Na Figura 9 também foi possível evidenciar a presença de elevadas densidades de coliformes termotolerantes nos pontos RD23 (à jusante de Rio Casca), RD33 (Belo Oriente) e RD44 (Governador Valadares), indicando uma necessidade de priorização quanto a investimentos para a implantação de estações de tratamentos de efluentes, ou a melhoria das existes. As concentrações de nitrato e fósforo total dos pontos RD59 (Resplendor), RD67 (Aimorés) e RD58, em Conselheiro Pena, mantiveram a mesma distribuição sazonal. Isso pode ser atribuído a uma maior estabilidade na água, após o ano de 2006, com o represamento feito pela UHE Aimorés e isso refletiu em maiores densidades de cianobactérias. Após a avaliação da série histórica dos parâmetros, considerando a variação sazonal, foi possível observar que não ocorreram alterações expressivas das concentrações de oxigênio dissolvido, no entanto, essas concentrações aumentaram mais no período estival. Isso se deveu principalmente a uma maior solubilidade, no caso do RD33 (jusante da Cachoeira Escura) ou a uma maior produtividade algal
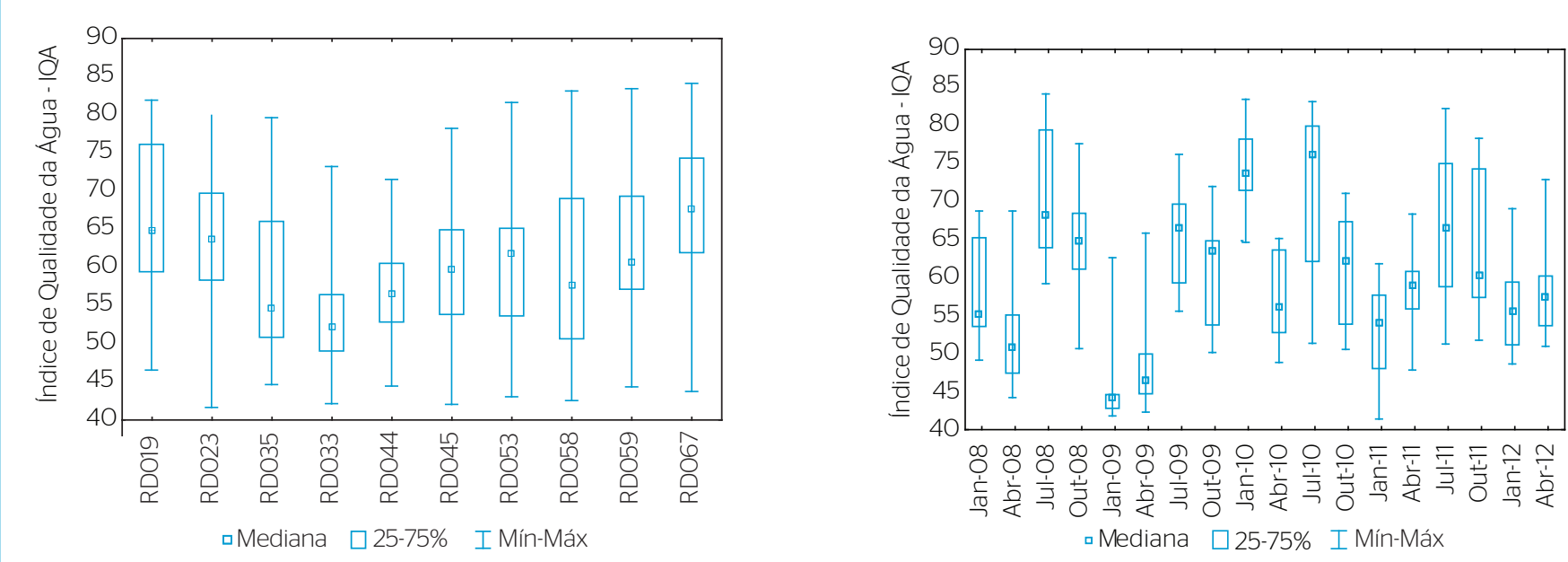

Figura 11 - Variações do Índice de Qualidade das Águas nos pontos avaliados no Rio Doce, entre 1997 e 2008 e ao longo dos meses no período de 2008 a 2012.

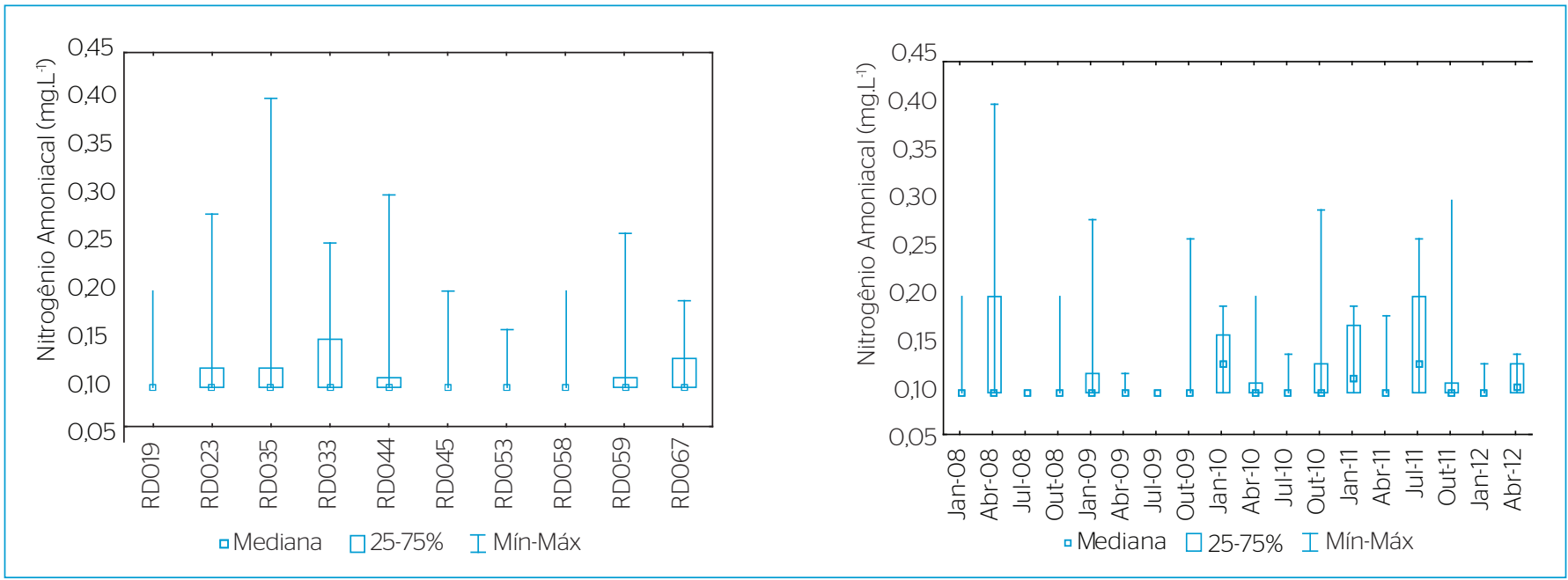

Figura 12 - Variações das concentrações de nitrogênio amoniacal nos pontos avaliados no Rio Doce, entre 1997 e 2008 e ao longo dos meses no período de 2008 a 2012. 
no caso do RD59 (jusante de Resplendor). As correlações $(<0,05)$ entre os parâmetros oxigênio dissolvido, nitrato, clorofila $a$, relação N/P e o IQA foram positivas com a densidade de cianobactérias. Relações N/P mais reduzidas foram detectadas no período chuvoso, que coincidiu também com um aumento na concentração de fósforo alóctone. Foi observada uma elevação dessa relação entre os meses de agosto e outubro e isso pode ter propiciado o predomínio de Dolichospermum nos últimos três anos. Embora ocorra a fixação de nitrogênio, há um menor gasto energético para a assimilação desse elemento na água. As concentrações de nitrato apresentaram também uma correlação positiva com a densidade de cianobactérias e a clorofila $a$ em todas as estações de coleta, no período estival, a partir de 2010. Observou-se também um aumento gradativo da concentração de nitrato ao longo dos anos (Figura 10). Essa elevação ocorreu principalmente devido aos processos oxidativos naturais do nitrogênio amoniacal, que foi maior no período chuvoso e/ou a própria contribuição direta de esgotos não tratados (Figura 12). Além disso, há a possibilidade da utilização do nitrogênio amoniacal pelas cianobactérias, pois a partir de 2009 verificou-se uma redução nas concentrações (abaixo de 0,3 mg. $\left.\mathrm{L}^{-1}\right)$ dessa espécie de nitrogênio.

O aumento na densidade das cianobactérias (Figura 2) ao longo do rio, de montante à jusante, foi diretamente proporcional às reduções nas concentrações de nitrogênio amoniacal (Figura 12). No período estival foram registradas as menores temperaturas e os mais baixos valores de turbidez na água, por outro lado, as mais

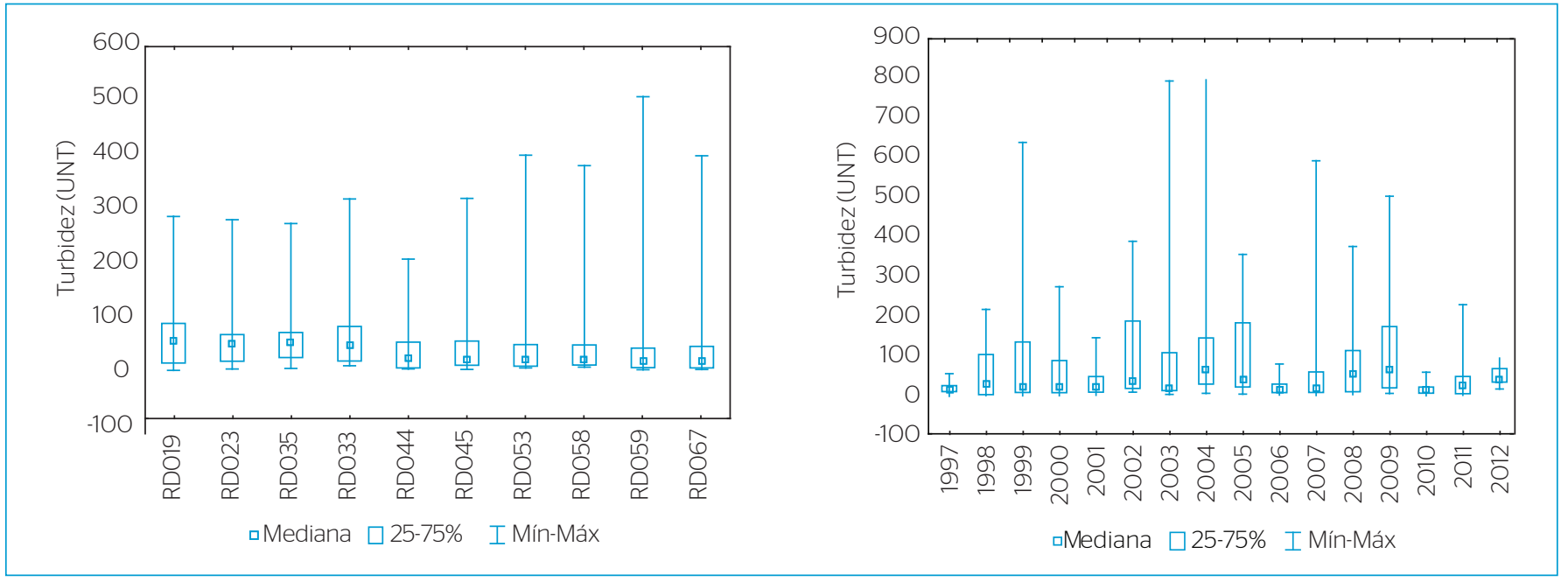

Figura 13 - Variações das medianas da turbidez nos pontos monitorados no Rio Doce e no período de 1997 a 2012.

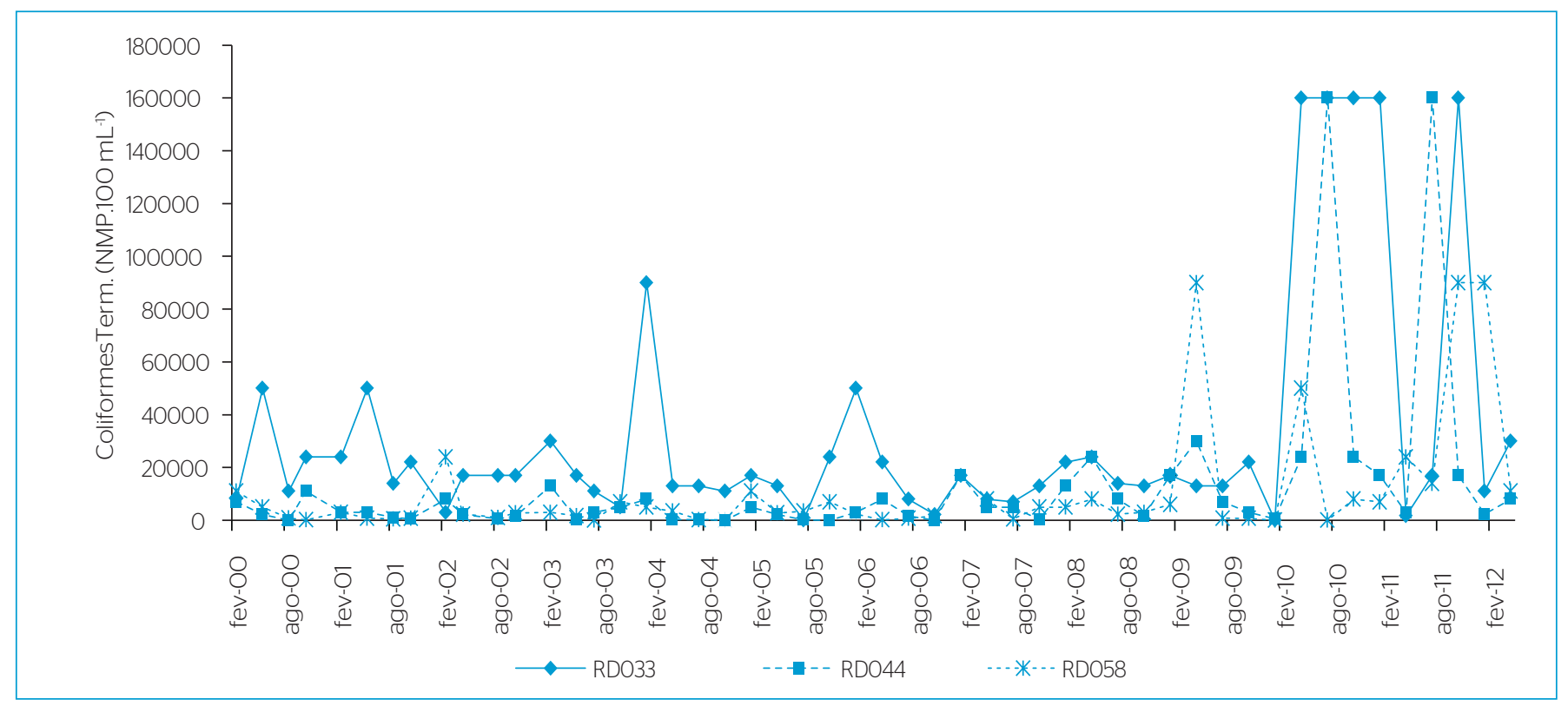

Figura 14 - Variações das densidades de coliformes termotolerantes nos pontos RD33, RD44 e RD58 no período de 2008 a 2012. 
elevadas concentrações de fósforo foram obtidas no período chuvoso, devido à contribuição alóctone de fontes pontuais e difusas. Isso ficou caracterizado nos pontos RD019, devido à adubação química do entorno e no RD033, oriundo dos efluentes gerados por uma lagoa de estabilização localizada a sua montante. Outra constatação que explica também a predominância dessas florações na água do rio se refere à turbidez, pois após 2010 esse parâmetro sofreu reduções significativas $(<0,05)$ com as medianas abaixo de 50 UNT (Figura 13). Essas reduções são mais comuns em águas superficiais, no período estival, quando represadas.

Como mostrado na Figura 14, observou-se uma elevação dos termotolerantes na água a partir de 2009, nos pontos RD33, RD44 e RD58, possivelmente devida ao aumento da contribuição de efluentes não tratados.

\section{CONCLUSÕES}

Verificou-se que as cianobactérias estiveram presentes na água do Rio Doce durante as estações secas dos anos de 2008 a 2012, nos 10 pontos de coleta avaliados no presente estudo. Na análise de agrupamentos entre as estações de coleta, o ponto RD44 se destacou isoladamente. Verificou-se uma relação entre a temperatura da água, o IQA, a turbidez e o oxigênio dissolvido. A temperatura da água variou nos meses mais frios dos anos avaliados, onde o IQA se mostrou mais elevado. O ponto de coleta RD33, localizado logo após a contribuição de esgotos tratados de uma lagoa de estabilização, pode ter contribuído com o aumento das concentrações de fósforo, nitratos, oxigênio dissolvido, densidade de termotolerantes e uma redução do IQA. Ficou evidenciado que as florações de cianobactérias em ecossistemas aquáticos lóticos, no caso do Rio Doce, foram diretamente coordenadas pelo regime hídrico, ou seja, foram muito mais densas na estação seca e fria, onde há uma redução da vazão na água do rio. Embora as florações de cianobactérias na água do Rio Doce sejam sazonais e dependam muito da extensão do período estival na bacia, ficou também caracterizada com esse trabalho uma crescente contribuição de nitratos e de coliformes termotolerantes na água do rio, nos anos de 2010, 2011 e 2012.

\section{REFERÊNCIAS}

AGÊNCIA NACIONAL DE AGUAS (ANA). (2012). Ocorrência de cianobactérias na bacia hidrográfica do rio Doce. Relatório Técnico 2012. Brasília (DF): ANA, 2012. 75 p.

COPASA - Companhia de Saneamento de Minas Gerais. Relatórios internos de qualidade da água - 2005 a 2012

Divisão de pesquisa e Controle de Qualidade da Água e Efluentes (2011). Procedimento Operacional Padrão n゚. 2.122 - Estimativa e Cálculo de Incerteza de Medição. Companhia de Saneamento de Minas Gerais.

COSTELLOE, J.F.; POWLING,J.; REID, J.R.W.; SHIEL, R.J.; HUDSON, P. (2005) Algal diversity and assemblages in arid zone rivers of the lake Eyre basin, Australia. River Research and Applications, v. 21, p. 337-349.

FERRAZ, H.D.A. (2012) Associação da Ocorrência de Clanobactérias às Variações de Parâmetros de Qualidade da Agua em Quatro Bacias Hidrográficas de Minas Gerais. 133 f. Dissertação (Mestrado em saneamento, Meio Ambiente e Recursos Hídricos) - Departamento de Engenharia Sanitária e Ambiental, Universidade Federal de Minas Gerais, Belo Horizonte, MG.

GOOGLE EARTH 2013. Google Earth: um servidor de mapas e informações geográficas. Desenvolvido pela Google Inc: Mountain View. Apresenta dados, mapas e imagens de satélite interativas da superfície da Terra. http://earth.google.com (acesso em 17/03/2013).

INSTITUTO BRASILEIRO DE GEOGRAFIA EESTATISTICA (IBGE).2010. Sinopse do censo demográfico 2010. Minas Gerais, 2010. Disponível em: <http//WWW. censo 2010. IBGE.gov.php?uf=31 \& dados = O > . Acesso em: 15 fev. 2013 .
INSTITUTO MINEIRO DE GESTÃO DAS AGUAS (IGAM). (2009). Monitoramento da qualidade das águas superficiais na bacia do rio Doce. Belo Horizonte (MG): IGAM, 2009. Disponível em: <http://aguas igam.mg.gov.br/aguas/htmls/downloads.htm>. Acesso em: 22 jul 2012.

JARDIM, B.F.M. (2011) Variação dos Parâmetros Físicos e Químicos das Águas Superficiais da Bacia do Rio das Velhas-MG e sua Associação com as Florações de Cianobactérias. 113 f. Dissertação (Mestrado em saneamento, Meio Ambiente e Recursos Hídricos) - Departamento de Engenharia Sanitária e Ambiental, Universidade Federal de Minas Gerais Belo Horizonte, MG.

JARDIM, F.A.; RESENDE, R.M.S.; LADEIA, M.M.; GIANI, A.; CERQUEIRA D.A.; JARDIM, B.F.M. (2008) Cyanobacteria blooms in waters of river intake areas in Minas Gerais - Brazil, during the dry season of 2007 Contingency Plants. In:Simpósio Italo-Brasileiro de Engenharia Sanitária e Ambiental, 9, 2008. Florença (Itália): ANDIS, CD-ROM.

MAIER, H.R.; BURCH, M.D.; BORMANS, M. (2001) Flow management strategies to control blooms of the cyanobacterium Anabaena circinalis, in the river Murray at Morgan, South Australia. Regulated River: Research \& Management, v. 17, p. 637-650

OLIVER, R.L.; MITROVIC, S.M.; REES, C. (2009) Influence of salinity on light conditions and phytoplankton growth in a turbid river. River Research and Applications, v. 26, p. 894-903.

ROBERTO, S.; ABREU, R.M. (1991) Utilidade dos indicadores de qualidade das águas. Ambiente, São Paulo, v. 5, n. 1, p. 47-51. 
SOARES, M.C.S.; HUSZAR, V.L.M.; ROLAND, F. (2007) Phytoplankton dynamics in two tropical rivers with different degrees of human impact (Southeast Brazil). River Research and Applications, v. 23, p. 698-714.

Standard Methods for the Examination of Water and Wastewater, American Public Health Association (APHA), American Water Works Association (AWWA) e Water Environment Federation (WEF), 22 ed., 2012.
VICINI, L. (2005) Análise multivariada da teoria à prática. Santa Maria, Monografia (Especialização em Estatística) - Departamento de Estatística, Universidade Federal de Santa Maria, Santa Maria (RS).

VON SPERLING, E.; JARDIM, F.A. (2009) Influence of climatic conditions on cyanobacteria blooms in a tropical water supply river In: 34 WEDC Conferences, 2009, Addis Abeba. 34 WEDC Conferences. Loughborough: Loughborough University. v. 1, p. 832-836. 